\title{
Shunt Piezoelectric Systems for Noise and Vibration Control: A Review
}

\author{
Konstantinos Marakakis, Georgios K. Tairidis, Panagiotis Koutsianitis and \\ Georgios E. Stavroulakis*
}

Computational Mechanics and Optimization Laboratory, School of Production Engineering and Management, Technical University of Crete, Chania, Greece

In this paper, the current state of the art on shunt piezoelectric systems for noise and vibration control is reviewed. The core idea behind the operation of electronic shunt piezoelectric circuits is based on their capability of transforming the dynamic strain energy of the host structure, i.e., a smart beam or plate, into electric energy, using the properties of the direct piezoelectric phenomenon and sending this energy into the electronic circuit where it can be partially consumed and transformed into heat. For this purpose, transducers which are made by piezoelectric materials are used, since such materials present excellent electromechanical coupling properties, along with very

OPEN ACCESS

Edited by: Vagelis Plevris,

OsloMet - Oslo Metropolitan University, Norway

Reviewed by: Antonio Formisano, University of Naples Federico II, Italy Dimitrios Giagopoulos, University of Western Macedonia, Greece

${ }^{*}$ Correspondence: Georgios E. Stavroulakis gestavr@dpem.tuc.gr

Specialty section:

This article was submitted to Computational Methods in Structural Engineering,

a section of the journal Frontiers in Built Environment

Received: 12 January 2019 Accepted: 29 April 2019 Published: 15 May 2019

Citation:

Marakakis $K$, Tairidis GK, Koutsianitis $P$ and Stavroulakis GE (2019) Shunt Piezoelectric Systems for Noise and Vibration Control: A Review. Front. Built Environ. 5:64. doi: 10.3389/fbuil.2019.00064 good frequency response. Shunt piezoelectric systems consist of an electric impedance, which in turn consists of a resistance, an inductance or a capacitance in every possible combination. Several types of such systems have been proposed in the literature for noise or vibration control for both single-mode and multi-mode systems. The different types of shunt circuits provide results comparable to other types of control methods, as for example with tuned mass-dampers, with certain viscoelastic materials, etc. As for the hosting structure, several studies on beams and plates connected with shunt circuits have been proposed in recent literature. The optimization of such systems can be performed either on the design and placement of the piezoelectric transducers or on the improvement and fine-tuning of the characteristics of the system, i.e., the values of the resistance, the inductance, the capacitance and so on and so forth. There are several applications of shunt systems including among others, structural noise control, vibration control, application on hard drives, on smart panels etc. Last but not least, shunt circuits can be also used for energy harvesting in order to collect the small amount of energy which is necessary in order to make the system self-sustained.

Keywords: shunt circuits, piezoelectrics, vibrations, control, acoustics

\section{INTRODUCTION}

Smart materials, such as piezoelectrics, piezoceramics, shape memory alloys, fiber optics, electrostrictive materials, magnetostrictive materials etc. can be integrated in structural models to provide them with the smart behavior. In principle, the initial stress or strain produced by some smart element can be controlled and leads to controlled, i.e., smart, behavior of the whole composite structure. Piezoelectrics constitute a suitable technology for testing smart structure concepts, since they have almost instantaneous reaction time without hysteresis and they work in most cases within 
the linarity range. An important thing here is that both sensing and actuation functions are possible due to the nature of the piezoelectric effect. This specific characteristic leads many investigators to deal with the passive control of vibrations by using devices with shunted piezoelectric elements (Thomas et al., 2009; Tairidis et al., 2018) in the form of an electric impedance.

This idea was first introduced in the innovative work of Forward (1979) who suggested the use of piezoelectric transducers in association with electric elements which he called shunt circuits for passive vibration control. The main concept consists of the transformation of the dynamic strain energy of the host structure into electric energy. This is achieved by using the direct piezoelectric effect and routing this energy into the shunt circuit where it can be partially consumed (see Figure 1).

In fact, shunt piezoelectric systems with an electric impedance can be very effective in structural vibration damping, thus they have been extensively studied during the past decades. Several shunting techniques have been developed based on different shunting methods, (Hollkamp, 1994; Moheimani and Fleming, 2006; Tairidis, in press), in order to deal with the energy which is produced by the structural vibrations. In these techniques, the energy is usually expressed in terms of loss factor or more often of a suitably defined damping ratio, depending on two distinct matters; the contribution of the electromechanical coupling and the design of the shunt system. Therefore, damping can be accurately predicted if the generalized coupling coefficient which describes completely the electromechanical coupling can be described (Delpero et al., 2012).

At this point, it is worth mentioning that in terms of dynamic behavior, certain types of shunt circuits present similarities with several other types of vibration control methods, as for example with tuned mass-dampers. Actually, as shown by Hagood and von Flotow (1991) and Wu (1996), among others, if the shunt circuit consists of a resistance $\mathrm{R}$, i.e., it is a pure resistive shunt, the dynamic behavior of the whole system is similar to the one of a viscoelastic material. In case of resonant, i.e., resistive-inductive (RL) shunt circuit, the influence of the circuit is analogous to the one of a viscously damped dynamic vibration absorber (Viana and Steffen, 2006).

Some even more sophisticated electronic shunt circuits for the increase of the damping capability of the system have been also proposed recently, as it will be shown in the following sections. Such systems include, among others, switched shunts (Ducarne et al., 2010) and negative capacitance circuits (Marneffe and de, 2008).

\section{PIEZOELECTRIC MATERIALS}

Piezoelectric materials are very attractive functional materials in smart structures because they can directly convert mechanical energy to electrical and via versa. In 1880, the piezoelectric phenomenon discovered by Curie and Curie (1881) initially discovered the direct piezoelectric effect in the tourmaline crystals. They found that a mechanical deformation in specific directions causes opposite electrical charges on opposite crystalline faces, which are proportional to the magnitude of the mechanical deformation. This phenomenon, which was also observed in quartz and other crystals without a center of symmetry, was called a piezoelectric phenomenon (from the Greek words " $\pi \iota \varepsilon \dot{\zeta} \zeta \iota \iota \nu$-piezein" that means to squeeze or press and " $\eta \lambda \varepsilon \kappa \tau o \nu$-ēlektron," which means amber, an ancient source of electric charge. This phenomenon is called the direct piezoelectric effect (as shown in Figure 2A). However, when an electric field is applied to the material a mechanical stress or strain is induced; this phenomenon is called the converse piezoelectric effect (see Figure 2B). However, the Curie brothers did not predict the reverse piezoelectric effect, which was mathematically deduced from fundamental thermodynamic principles by Lippmann (1881).

Piezoelectric materials present very good electromechanical coupling properties, as well as excellent frequency response, due to their nature. Thus, such materials have been extensively used in vibration control of smart structures, in structural health monitoring, energy harvesting, optimal positioning, etc. The direct phenomenon is mainly used in sensors (detection of structural flaws, vibration suppression, etc.) or for the harvesting of the energy which is produced by the vibrations. On the other hand, the reverse phenomenon is mainly used on actuators. Piezoelectric transducers are available in many forms and shapes, usually in thin sheets, and are capable of producing forces from applied voltages.

Piezoelectric materials exhibit, also by their nature, a nonlinear behavior, which is reinforced by their complex grain and domain structure. The understanding of the properties of such materials over a large range of parameters (e.g., temperature, frequency, stresses, etc.) is essential. The knowledge of the electroelastic constitutive behavior is very important in order to predict the response of a structure with embedded piezoelectric sensors and actuators. The non-linear behavior of piezoelectric ceramics is outlined among others in Mukherjee et al. (2001) and Albareda and Pérez (2011). A focused, multidisciplinary review on the field-dependent nonlinear piezoelectricity is provided by Benjeddou (2018). The non-linear constitutive equations for piezoceramic materials are given in detail in Joshi (1992). The analytical modeling of non-linear piezoelectric transducers is investigated, among others, in Mack (2003). According to Mack (2003) a possible reason of the occurrence of non-linearities is the interaction between isotropic elements and the anisotropic piezoelectric sensor.

Optimal control of smart structures with the use of piezoelectric sensors and actuators on vibration suppression was presented in Stavroulakis et al. (2005). Two different control schemes, i.e., LQR and $\mathrm{H}_{2}$ control, are compared. The results have shown that sufficient vibration suppression can be achieved in smarts structures with the use of piezoelectric materials.

In Buchacz et al. (2013) the control of the characteristics of a piezoelectric mechatronic system is investigated. More specifically, two examples of systems with piezoelectric transducers are considered in order to examine the suppression of vibrations; a single piezoelectric plate glued on a mechanical subsystem surface, and a piezostack, i.e., a set of piezoelectric plates vibrating in a thickness mode. In both cases, the 


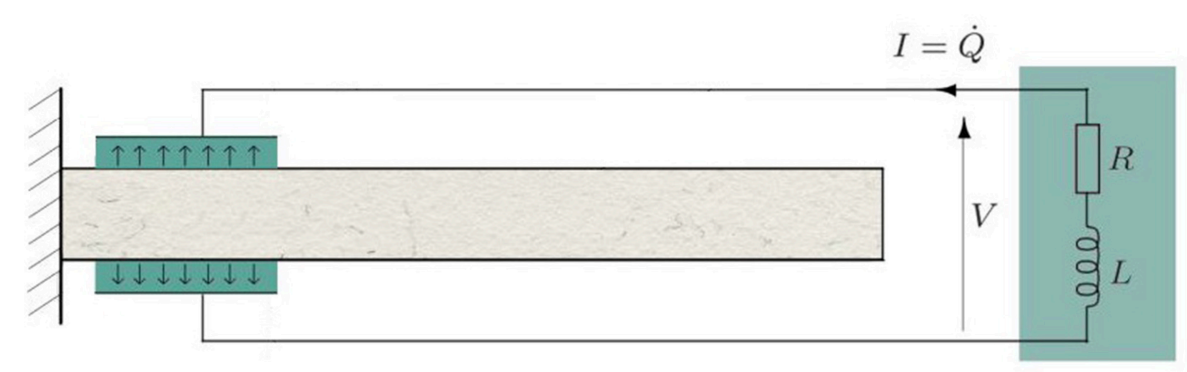

FIGURE 1 | A beam model with a resonant shunt piezoelectric circuit.

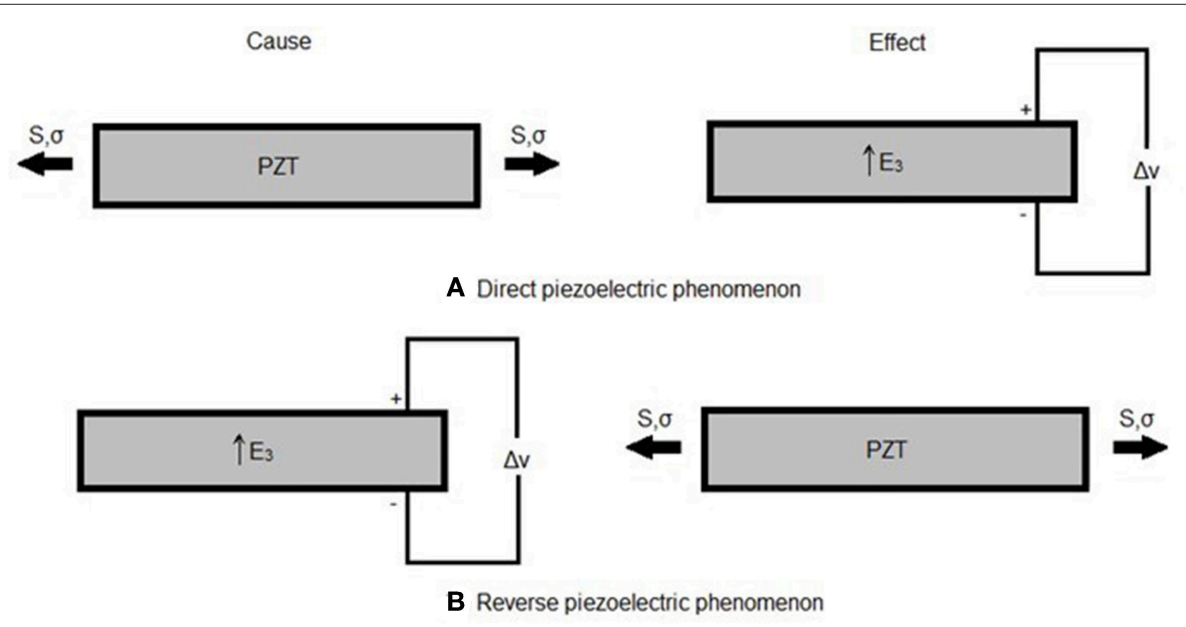

FIGURE 2 | (A) Direct piezoelectric phenomenon, (B) Reverse piezoelectric phenomenon.

desired characteristics of the studied systems were generated and presented.

\section{DESCRIPTION OF SHUNT PIEZOELECTRIC SYSTEMS}

Shunt systems, also known as shunt piezoelectric systems, are electric circuits connected with piezoelectric elements (e.g., PZT patches, piezoelectric transducers, etc.). Such systems are mostly passive, however, recently, also semi-passive or even active systems have been proposed.

During passive shunt control, a piezoelectric actuator is necessary in order to convert the mechanical energy, which is produced by the vibrations of the structure, into electrical energy. This energy is transferred to the electric elements of the shunt circuit in order to be destroyed, and thus to suppress the vibrations (Corr and Clark, 2003; Fleming and Moheimani, 2004).

The use of piezoelectric patches connected with resistive shunt circuits, i.e., circuits with only a resistance, was first proposed by Hagood and von Flotow (1991). The proposed formulation provided an equivalent vibration damper. Regarding structural damping, resonant shunt circuits (resistive inductive) can also be very useful for the control of single modes. These systems are characterized by the need for specific inductance and resistance values in order to reach the optimum values in terms of vibration attenuation. This is due to the fact that the passive control system uses the principle of dynamic absorbers by tuning the resonance frequency of the shunt circuit to the natural frequency of the structural system. These circuits are equivalent to vibration absorbers within a narrow frequency range.

In general, shunt circuits can be roughly classified into passive and active. Another categorization of these circuits can be into linear and nonlinear. Several approaches with resonant, resistive, capacitive, and switching shunts have been proposed (Niederberger, 2005). The most common shunt circuits are depicted in Figure 3.

\section{Piezoelectric Shunt Damping}

The basic principles of passive damping with shunted piezoelectric elements are analytically presented in the very recent book of Preumont (2018). Resistive, inductive and resonant shunting are examined. Moreover, several ways of tuning of such systems in terms of inductance are discussed, along with the capabilities of synchronized switch damping. The 


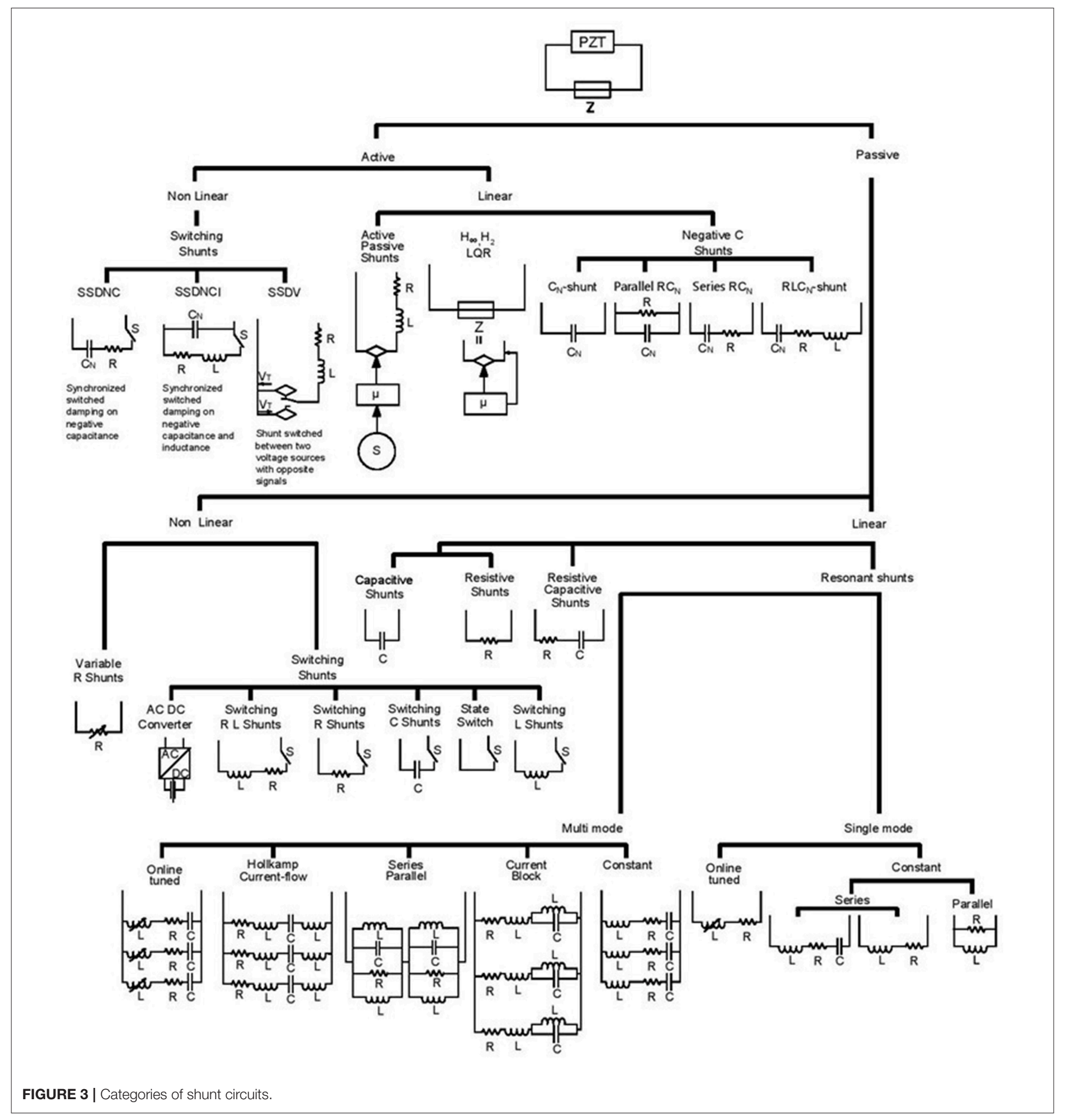

idea of active damping with shunted piezoelectric elements is discussed, among others, in the book of Preumont (2006).

Semi-passive shunt electrical components are used for the tuning of vibration controllers in McDaid and Mace (2016). The system consists by an electromagnet with an adaptive synthetic shunt impedance. The design of the system allows self-tuning and maintenance, even when variations in excitation frequency, environmental conditions or shape properties are present. The control system consist of two different types of controllers and many algorithms for each type are used. Experiments demonstrate that the linear controller is not reliable, however, some good results are obtained for polynomial and fuzzy controllers. The proposed control system adjusts very well to variable excitation frequencies, it is stable and performs efficiently for different modifications of the system's parameters. An RC shunt, i.e., a circuit of a resistor and a capacitor, is developed, and its parameters are adapted online in order to achieve optimal tuning. The results are verified experimentally. 
A semi-passive damping technique is presented in Liu and Vasic (2013). The proposed method is based on pulse-width modulation and it can significantly increase the structural damping of the system. With this method, the waveform of the piezoelectric voltage accommodates to the vibration velocity, the system has a stable voltage source and at the same time the performance is increased. The theoretical part of the investigation is also experimentally proved.

The synthesis of electromagnetic shunt impedances for vibration control of structures is studied in Behrens et al. (2004). Namely, a technique of sensor-less active shunt control for application to a mechanical vibration system is proposed. For the minimization of structural vibrations, an electrical impedance was designed and connected to an electromagnetic element. Common control tools were used to design the required shunt impedance. The application of an active shunt impedance reduced the vibration of the structure without the use of any additional feedback sensors.

As an alternative to the above, negative capacitance shunt systems have also been examined by many authors. Among others, Marneffe and de (2008) study a scheme for vibration damping with negative capacitance shunts both theoretically and experimentally. Namely, the enhancement of piezoelectric transducers by means of negative capacitive shunting is considered. Two different implementations are investigated; one in series and one in parallel. The results indicated the lack of robustness of the parallel system. From the experimental results on a truss structure it is shown that the damping which is introduced by the negative capacitance shunt system is larger than the damping which is obtained by the passive shunt circuits.

\section{General Electromechanical Equations of Shunted Piezoelectric Systems}

The general electromechanical equations which describe the behavior of piezoelectric materials are defined in the IEEE Standard on Piezoelectricity (American National Standards Institute et al., 1987):

$$
\left\{\begin{array}{l}
T \\
D
\end{array}\right\}=\left[\begin{array}{cc}
c^{E} & -e \\
e^{t} & \varepsilon^{s}
\end{array}\right]\left\{\begin{array}{l}
S \\
E
\end{array}\right\}
$$

After Hamilton's principle and discretization with finite elements for coupled electromechanical systems (Thomas et al., 2009) one has:

$$
\left[\begin{array}{cc}
M & 0 \\
0 & 0
\end{array}\right]\left\{\begin{array}{l}
\ddot{w} \\
\ddot{v}
\end{array}\right\}+\left[\begin{array}{cc}
C & 0 \\
0 & 0
\end{array}\right]\left\{\begin{array}{l}
\dot{w} \\
\dot{v}
\end{array}\right\}+\left[\begin{array}{cc}
K & \Theta \\
\Theta^{t} & -C_{p}
\end{array}\right]\left\{\begin{array}{c}
w \\
v
\end{array}\right\}=\left\{\begin{array}{c}
F \\
q
\end{array}\right\}
$$

The equation of motion of the coupled piezoelectric electromechanical system, as described in Equation (2), can be rewritten as a set of two coupled equations (Jeon, 2009a,b):

$$
\begin{gathered}
[M]\{\ddot{w}\}+[C]\{\dot{w}\}+[K]\{w\}]+[\Theta]\{v\}=\{F\} \\
{[\Theta]^{t}\{w\}-\left[C_{p}\right]\{v\}=\{q\}}
\end{gathered}
$$

The first equation describes the equilibrium state of mechanical forces, while the second one gives the electromechanical state of the electric potential. These two equations are used to describe the piezoelectric passive damping force from the piezoelectric shunt damping system, which is connected with the electrodes, to the host structure.

The electric voltage across the piezoelectric patches and the shunt circuit can be represented by the current-voltage ratio in the Laplace domain:

$$
V_{s h}(s)=Z_{s h}(s) \cdot I_{s h}(s)
$$

Substituting in Equation (4) the electric current $I_{s h}(s)$ with the derivative of the electric charge $\dot{q}(s)$ from the second part of Equations (3), one obtains the relation:

$$
V_{s h}(s)=Z_{s h}(s) \cdot \dot{q}(s)=Z_{s h}(s) \cdot\left([\Theta]^{t}\{w\} s-\left[C_{p}\right] V_{s h}(s) s\right)(5)
$$

Solving Equation (5) for $\mathrm{V}_{\mathrm{sh}}(\mathrm{s})$, we have the relation:

$$
V_{s h}(s)=\frac{Z_{s h}(s)[\Theta]^{t}\{w\} s}{1+Z_{s h}(s)\left[C_{p}\right] s}
$$

where $s$ is the Laplace operator.

Substituting the Equation (6) in the first equation of Equation (3) we obtain the relationship of the shunted piezoelectric system where the additional passive piezoelectric damping force is considered:

$$
[M]\{\ddot{w}\}+\left([C]+Z_{\text {total }}[\Theta][\Theta]^{t}\right)\{\dot{w}\}+[K]\{w\}=\{F\}
$$

where the inherent capacitance $Z_{\text {total }}$ of the system includes the total electric impedance of the shunted piezoelectric $Z_{s h}$ as:

$$
Z_{\text {total }}=\frac{Z_{s h}}{1+Z_{s h}\left[C_{p}\right] s}
$$

Equation (7) can be transformed into the modal domain using the following modal coordinates:

$$
\{w\}=[\Phi]\{\xi\}
$$

Substituting Equation (9) into Equation (7) and transforming into the frequency domain, one can obtain the uncoupled equations of motion for harmonic vibrations in the modal domain:

$$
\begin{aligned}
& -\omega^{2}[m]\{\xi\}+j \omega\left([c]+Z_{\text {total }}[\Theta]\right)+[\kappa]\{\xi\}=\{f\} \\
& \{\xi\}=\left(-\omega^{2}[m]+j \omega\left([c]+Z_{\text {total }}[\Theta]\right)+[\kappa]\right)^{-1}\{f\}
\end{aligned}
$$

\section{Piezoelectric Shunt Acoustic Control}

Piezoelectric shunt acoustic control is a more general term, i.e., a superset, of piezoelectric shunt damping, as it includes also systems without damping. The core idea behind this concept for vibration control of mechanical systems is depicted in Figure 4.

For the case of acoustic systems (see Figure 5), the piezoelectric transducer is embedded into the system and acoustic pressure is applied. The piezoelectric element is used 


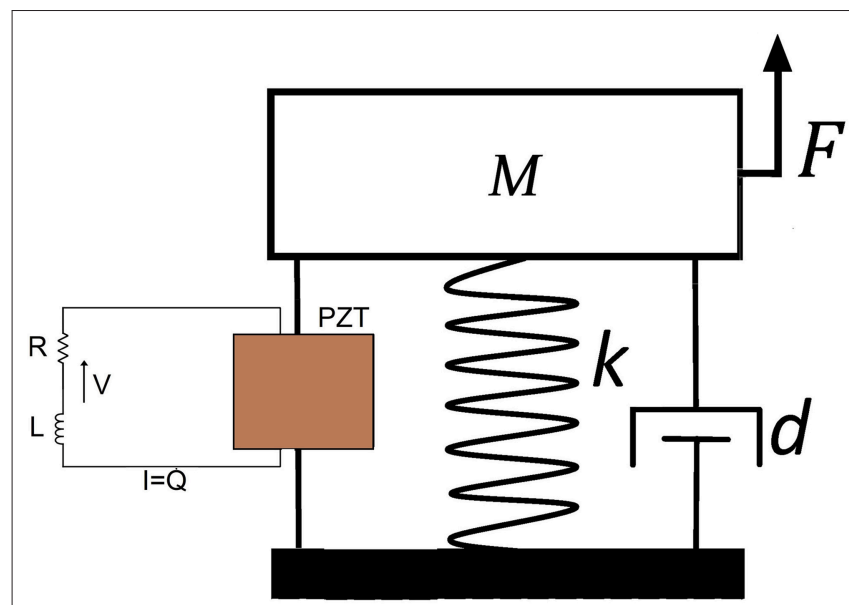

FIGURE 4 | The concept of the piezoelectric shunt acoustic control for vibration control of mechanical systems (shunt damping).

for the deterioration of acoustic signals in the same way it does for the mechanical vibrations. This approach was suggested by Forward (1979) and Forward and Swigert (1981). In these studies, a single piezoelectric element is used between the host structure and the electrical shunt circuit, in a form of a passive resistor or a resonant circuit.

The greater part of the published studies in the field of piezoelectric shunt acoustic control has mainly focused on resonant shunt circuits for the control of vibration and more specifically on vibration damping.

\section{Shunted Piezoelectric Circuits Single Mode Shunt Circuits}

A finite element formulation, as well as, a reduced-order model is proposed for the piezoelectric shunt vibration damping of structural-acoustic systems (Deü et al., 2014). This model is used for the approximation of a fully coupled electromechanical system using modal projection techniques. The piezoelectric patches, along with bonded resonant shunt circuits, are considered for the suppression of the vibrations of the coupled system. The numerical results illustrate the accuracy and the adaptiveness of the proposed reduced-order model, regarding the requested attenuation.

Another efficient finite element formulation, along with a suitably defined set of electromechanical coupling coefficients for an elastic structure with shunted piezoelectric circuits is sought in Thomas et al. (2009). More specifically a numerical simulation with application for control, sensing and vibration reduction is conducted. In parallel, a reduced-order model using modal techniques is proposed in order to show that the electromechanical coupling coefficients are the main parameters in coupling. The results are verified by an application on a cantilever beam.

Numerical modeling of noise and vibration reduction of thin radiating structures in the low frequency range is presented from (Silva et al., 2014). Piezoelectric patches which connected with two types of electrical shunted circuits (resonant and resistive) are used for the analysis. The parameters of placement and size of the piezoelectric patches are optimized with objective the adoption of better results in terms of the reduction of structural vibrations and acoustic radiation.

In Andreaus and Porfiri (2007) the problem of the effect of variations of the electric impedance with respect to its optimal selection in an electric network for resonant piezoelectric shunting system is analyzed.

Two novel electromagnetic shunt damping vibration isolators (EMSD-VIs) are proposed in Yan and Zhang (2012). The aim of the work is the isolation of vibrations of a beam structure. A pair of electromagnetic coils along with a box-shaped spring with variable damping are used. The negative resistance is introduced in order to improve the performance of the isolation system. The design rules of the shunted negative resistance are obtained by stability analysis. An experimental validation of the proposed theoretical model is also carried out.

A detailed study which focuses on the optimization of piezoelectric actuators which are shunted with LR Impedances is presented in Berardengo et al. (2015). Namely various algorithms are used to optimize the values of the electric components of the shunt impedance in order to achieve better performance and guarantee the robustness of the whole system. The algorithms which are presented are in compliance with the tuned mass dampers theory, which is used also for comparison. Analytical and numerical results are confirmed by the ones of a corresponding experiment.

The damping of structural vibrations with piezoelectric materials and passive electrical networks is studied in the work of Hagood and von Flotow (1991). The shunted piezoelectric circuit add some frequency dependent stiffness to the system. The general model is specialized for two different circuits; one with only a resistor (resistive shunt) and one with a resistor and inductor (resonant shunt). The material presents viscoelastic behavior in the case of the resistive shunt, however, when it comes for the resonant shunt with a resistor and an inductor, an electrical resonance is introduced to the system, which in turn can be tuned to structural resonances. An experiment on a cantilevered beam is conducted and the results validate the shunted piezoelectric damping models.

\section{Multimode Shunt Circuits}

A new method regarding the use of shunted piezoelectric transducer patches (PZT) for vibration reduction of multiple modes is presented in Fleming et al. (2000). Namely, it is proposed that the vibrational mechanical energy of a structure can be consumed via an electrical impedance by the PZT patches. This method used an arbitrary impedance using a current source and a digital signal processor.

According to Viana and Steffen (2006) the analytical model of passive vibration damping using piezoelectric patches with resonant shunt circuits shows that the general behavior of shunted piezoelectric systems is similar to the classical dynamic vibration absorbers. The study presents interesting analytical and experimental data concerning the design of the interlaced circuits with synthetic inductors. 


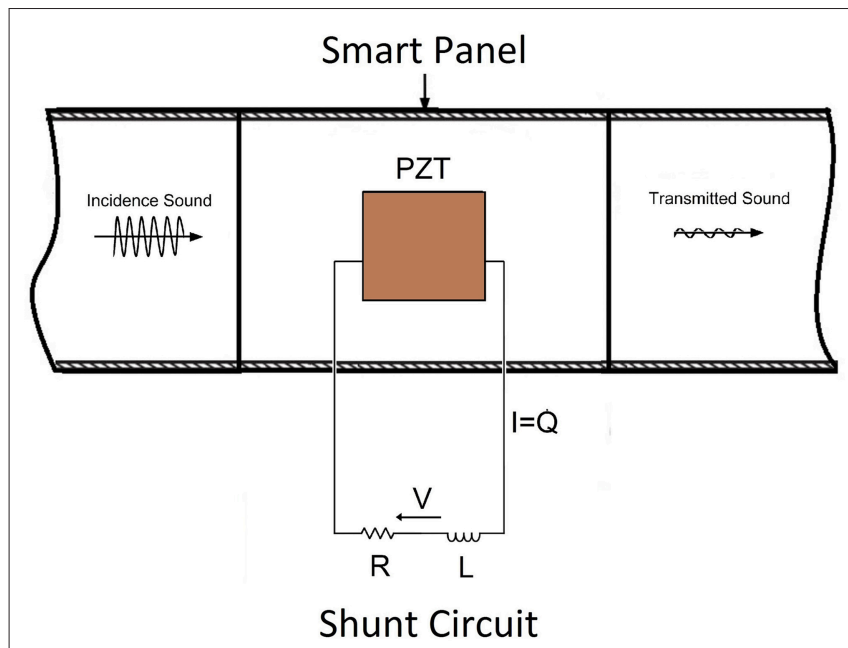

FIGURE 5 | The concept of the piezoelectric shunt acoustic control for control of noise (sound transmission) on a smart panel.

Moreover, Cheng et al. (2009) have employed a multiple current flowing electromagnetic shunt damper for semiactive vibration suppression of flexible structures. The system was electromagnetically-mechanically coupled between the electric circuit and mechanical beam vibration by using an electromagnetic transducer.

A multi-mode passive piezoelectric shunt model is proposed in Berardengo et al. (2017). The shunt damping is investigated by means of matrix inequalities, while the involved impedance is treated as a controller of the electro-mechanical system. The paper focuses on passive multi-mode vibration control in order to find the optimal impedance. The proposed method successfully overcomes the difficulties of multi-mode shunt control strategies. The results of the investigation show the capability of the matrix inequality method to provide sufficient damping. An experimental verification is also carried out.

In the work of Goldstein (2011) a method for the design and online adaptation of multimodal piezoelectric resonant shunts is discussed. The difference between the proposed method and other multi-modal shunting methods, such as current blocking and current flowing, lies to the implementation of the shunting network. Namely, a reduced number of discrete electrical components is used for the online tuning of the parameters of shunt system. The mathematical model provides the coupled equations of motion of the structure with piezoelectric elements and passive shunt networks. The design of the multimodal shunt network is presented based on passive filter synthesis methods. An experimental demonstration of the proposed multimodal self-tuning damper is also presented.

An online tuned multi -mode resonant piezoelectric shunt controller for vibration attenuation is proposed in Niederberger et al. (2004). For the optimal adjustment of the shunt parameters, the relative phase difference between a vibration reference signal and the shunt current is minimized. The proposed technique is validated by experiments. More specifically, it is demonstrated that the damping of two structural modes can be achieved at the same time. The convergence of the adjustment is quick and optimal performance in the presence of uncertainties is maintained.

In Nguyen and Pietrzko (2006) a finite element analysis of a piezo-actuated adaptive aluminum beam with vibration damping which use an electric multiple-mode shunt system is considered. Electric finite elements are used in order to simulate explicitly the R-L shunt circuit. Calculations are also extended to a multiplemode shunt system, where each branch consists of a parallel R-L shunt circuit in series with two C-L circuits in order to block two different resonance frequencies. The results indicated that in the modified system, only the half of the circuits are needed.

Multiple-mode structural vibration control using negative capacitive shunt damping is studied in Park and Park (2003). A novel shunt piezoelectric circuit, capable of attenuating multimode vibration amplitudes by using a pair of piezoceramic patches is presented. The damping mechanism is described considering a voltage which is constrained by the impedance of the shunt circuit. The presented numerical results indicate that the piezoelectric beam model combined with a series and a parallel resistor-negative capacitor branch circuit can suppress multiple-mode vibration amplitudes over a frequency range of interest with respect to the dynamic response of the whole structure.

Multimodal passive vibration control of sandwich beams with shunted shear piezoelectric materials is investigated in Trindade and Maio (2008). The performance of a multimodal passive vibration control scheme, based on independent resistive shunt circuits, is studied. The shunt control scheme is applied on a sandwich beam core using shear piezoelectric materials. The numerical results indicate that modal damping factors of $1 \%-2 \%$ can be obtained for three selected vibration modes.

An F-15 panel was tested in acoustic excitation in $\mathrm{Wu}$ et al. (2000). The aim of proposed method was to examine the ability of the system with bonded piezoelectric elements to control and survive of high acoustic excitation levels, and to investigate the piezoelectric shunt-damping technique at these excitations. Single- and multiple-mode shunting systems were used in order to suppress the first two modes. For this purpose, many piezoelectric components, along with two shunt electric circuits were used. Experimental results are also presented with details.

The use of piezoelectric transducers, shunted with a multiterminal network, in multimode vibration control is presented in Giorgio et al. (2009). The reduction of vibrations for one- and two-dimensional mechanical structures of shunted piezoelectric transducers with electric networks is studied. Namely, a method for controlling " $n$ " structural modes by " $n$ " piezoelectric transducers shunted with an electric network system is presented. The proposed technique can be classified as a virtual passive damping method.

Lastly, a different approach for the control of several modes is proposed by Tairidis (in press). According to this study, vibration control of different modes can be achieved considering a set of optimized resonant shunt piezoelectric circuits in combination with an intelligent adaptive neuro-fuzzy control system. In this approach, shunt circuits can be pre-tuned to the first four eigenfrequencies and the control system can be used for the 
activation of the suitable shunt circuit, each time. This makes the whole system not only adaptive, but effective as well.

\section{Switching Shunt Systems}

An autonomous piezoelectric shunt damping system is described in Fleming et al. (2003a). More specifically, an efficient, lightweight, and small-in-size technique for implementing switchedmode piezoelectric shunt damping circuits is presented. The experimental results demonstrate the effectiveness of the shunt circuit implementation, as with the current-flowing shunt circuit, two modes of a simply supported beam were successfully reduced in amplitude by 21.6 and $21.3 \mathrm{~dB}$, respectively. The development of a device which connects research and practical application is also discussed.

Another autonomous shunt circuit for vibration damping is presented in Niederberger and Morari (2006). In this study, an implementation of an autonomous switching resonant (RL) shunt circuit for the reduction of structural vibrations is described. The resulting circuit does not require power for its operation and is almost as effective as a classic shunt. Moreover, experiments show that the damping performance is robust against temperature variations which are caused due to environmental conditions, whereas other shunt circuits lose their damping performance. The proposed system requires only a minimum number of electronic components; therefore, it can be considered as an effective solution for the control of vibrations.

A third application on autonomous shunt circuits is presented in Niederberger (2005), where a hybrid system for the development of an optimal control system for vibrational damping is studied. More specifically, the system obtains the optimal laws for the switching of the circuits. Multi-parametric programming allows to the calculation of the switching law which is necessary for the partitioning of the state-space into regions where the switch is either open or closed. The electronic shunt circuit requires a small amount of power for its operation, which in some cases can be neglected. From the experimental results it is shown that the proposed autonomous damping circuit could suppress vibrations, but it is not as effective as a standard resonant shunt circuit.

In Ducarne et al. (2010), structural vibration reduction by switch shunting of piezoelectric elements is discussed. More specifically, the study deals with modeling and optimization in terms of the reduction of structural vibrations by means of synchronized switch damping techniques on piezoelectric elements. The electrical impedance is selected either as a simple resistance, which produces a synchronized switch damping on short circuit or a resistance and an inductance in series, where a synchronized switch damping occurs on the inductor. The extra damping which is added by the piezoelectric device is also estimated. From the results it is concluded that the only parameter which needs to be optimized is the piezoelectric coupling factor. In fact, if this parameter is maximized, the damping which is added to the system is maximized as well.

In Collinger et al. (2009) a new vibration control method on beams is presented. The controller is synchronized in every change of the parameters of the system (mass, stiffness, and excitation) and dissipates the maximum amount of energy.
The simulation takes into account the coupled dynamics of the structure and piezoelectric circuit to obtain the general coordinates between the sets of modes for the open- and closedswitch modulation. With this method, the time instants of the optimal switching procedure are recognized through a filtered velocity signal. A fuzzy logic algorithm is used in order to maximize depreciation. The efficacy of the method is confirmed by laboratory tests on a headlamp driven by the stimulation of the base and two piezoelectric elements attached to the beam for vibration control.

In Chen et al. (2013) a self-powered damping system based on zero-velocity crossing detection is presented. The control signal is obtained from a velocity sensor which controls the switches of the system. The system does not require any type of external energy, except from the one which is harvested using the synchronized switch damping on inductor (SSDI) technique. The proposed technique has the advantage of no delay switching time, in comparison with the one based on a voltage peak detector. The self-powered technique has been also experimentally tested.

An aggregation of the advantages and disadvantages of the several types of shunt systems which are reviewed in the present paper is outlined in Table 1.

From the investigations which are reviewed in the present paper, it is found that resonant shunts, i.e., circuits with inductors and resistors which are tuned around natural frequencies, are the most efficient, in terms of damping of several structures and systems.

\section{Shunt Systems on Composite Structures}

Several investigations on beam structures with piezoelectric materials connected with shunt circuits have been proposed in literature. For example, in Lossouarn et al. (2017), a possible design of inductors with high inductance values for resonant piezoelectric damping, which takes into account practical limitations which usually appear in the low frequency range is presented. The electrical elements are integrated into a piezoelectric shunt circuit which is dedicated to the control of vibrations of a cantilever beam. From the results of the analysis, it is shown that specific designs can extend the application of passive resonant shunt strategies, especially for lower frequencies.

In Isola et al. (2004), the passive damping of beam vibrations through distributed electric networks and piezoelectric transducers is studied. The aim of the paper is to present a design of a device for damping, along with experimental validation. For this purpose, two different electric networks were used; a purely resistive network and an inductive-resistive (resonant) one. The feasibility and the effectiveness of the proposed methods, in terms of structural damping, were validated through an experiment, presenting very good agreement with the numerical results.

A passive modal damping method using piezoelectric shunts is presented in Granier et al. (2002). More specifically, piezoelectric materials are used in conjunction with passive inductance-resistance-capacitance (RLC) shunt circuits in order to provide vibration damping in specific modes. The piezoelectric transducers are used for the conversion of mechanical energy into electrical, which, in turn, is consumed in the shunt circuit as heating. In order to test the circuits, an impulse 
TABLE 1 | Comparison of shunt systems and methods.

\begin{tabular}{|c|c|c|}
\hline Shunt systems & Advantages & Disadvantages \\
\hline Single-mode & Easy to implement and tune & $\begin{array}{l}\text { Limited capabilities and applicability in real-life } \\
\text { applications, medium efficiency }\end{array}$ \\
\hline Multi-mode & $\begin{array}{l}\text { Wide range of applicability, easy to implement, increased } \\
\text { efficiency }\end{array}$ & Increased complexity, hard to tune \\
\hline Switching & Wide range of applicability, increased efficiency & Delay of response, increased complexity \\
\hline Resistive (R) & Easy to implement and tune & $\begin{array}{l}\text { Very limited capabilities and real-life applications, poor } \\
\text { efficiency }\end{array}$ \\
\hline Resonant (RL) & $\begin{array}{l}\text { Easy to implement, wide range of applicability, increased } \\
\text { efficiency }\end{array}$ & Not always easy to tune \\
\hline Resistive-Inductive-Capacitive (RLC) & Wide range of applicability, increased efficiency & Not always easy to implement and tune \\
\hline Negative capacitance & $\begin{array}{l}\text { Increased efficiency, applicability in specialized real-life } \\
\text { applications }\end{array}$ & Increased complexity, hard to tune \\
\hline Synthetic impedance & Applicability in specialized real-life applications & Increased complexity, not always easy to tune \\
\hline
\end{tabular}

is applied to a simple cantilever beam and the parameters of the RLC circuit are tuned in order to provide the desired damping.

Piezoelectric RL shunt damping of flexible structures, and more specifically of piezoelectric beams, is discussed in Høgsberg and Krenk (2015b). The calibration of the involved parameters is based on the equal damping of the two eigen modes which are associated with the resonant vibration of the structure. A quasi-static contribution from the non-resonant vibration modes of the structure is also included in the analysis, which leads to explicit calibration expressions for the circuit components. A simple numerical example indicates the effectiveness of the proposed scheme.

Resonant shunt circuits with piezoelectric elements bonded on a thin beam are studied in Hassan et al. (2011). Resonant RL shunt circuits, both in series and in parallel are considered. An iterative process based on finite elements is used in order to find the optimum values of the resistance and the inductance of the system.

A piezoceramic shunted damping concept regarding testing, modeling and correlation on cantilever long beams, which are bonded with single pairs of small piezoceramic patches symmetrically on both surfaces, upper and lower, is presented in Chevallier et al. (2009). Experimental results are used for the evaluation and the assessment of the shunted damping concept of the host structure. The efficiency of the proposed technique is measured by the modal effective electromechanical coupling coefficient, which is calculated from free-vibrations analyses under short- and open-circuit formulations. ABAQUS commercial software is used for the finite element analysis.

In Fleming and Moheimani (2005), a method for the design and the implementation of high-performance piezoelectric shunt impedances in order to control mechanical vibrations is presented. The shunt impedance design can be accomplished by solving a common control problem with parameters the transducer voltage inputs and charge outputs. The impedance which occurs from the proposed method has been compared experimentally with a resonant shunt system on a cantilever beam. The results of the experiment have shown significant reduction of vibrations of the structure in the first mode of the cantilever.

In Buchacz and Płaczek (2011) a one-dimensional flexural vibrating mechatronic system is studied. The system includes a cantilever beam with piezoelectric elements connected with an electric circuit for the damping of vibrations. The Galerkin method was used to analyze the system. The damping of the structure was taken into account. Kelvin-Voigt model of materials was used for the introduction of Rheological properties. The results of the proposed method were presented in 3D graphs.

In the work of Schoeftner and Irschik (2009), passive damping and vibration suppression of beams using shaped piezoelectric layers and tuned inductive networks is studied. More specifically, the study is focused on the development of an extended Bernoulli-Euler beam theory for passive piezoelectric composite structures which considers also the presence of electric networks. From the results it is shown that control of vibrations for a cantilever beam is possible, under certain conditions for the electric elements. In another work of the same group (Schoeftner and Irschik, 2011), a comparative study of smart passive piezoelectric structures interacting with electric networks is carried out. The results from Timoshenko's beam theory are compared with finite element calculations of plane stress.

During the last three decades, several investigations on the use of piezoelectric transducers for the vibration control of thin plate-like structures have been carried out by many authors. In the work of Saravanos (1999), the damping of vibrations of composite plates with passive piezoelectric-resistor elements is studied. It is shown that, for each mode, there is an optimal value of the resistance which adds significant modal damping. Away from this optimal value the damping gradually reduces to zero.

Vibration control of plates with passive electrical dampers made of shunted piezoelectric materials is studied in Park et al. (2005). The electrical absorber, which is proposed in this paper, consists of piezoelectric patches connected with a resistor and an inductor in series and can be considered as an equivalent to the damped mechanical vibration absorber. In order to estimate the effectiveness of the absorber, the equations of motion are derived by the classical laminate plate theory and Hamilton's principle. The theoretical analysis is also experimentally validated for the 
simply supported plates and the performance of the passive electrical damper is demonstrated. The resulted model can be used in many engineering applications.

Electrical tuned vibration absorbers are studied by Tondreau et al. (2014). Namely, an application of the equal-peak method to linear and non-linear RL piezoelectric shunts is presented. The major contribution of this study to the current state of the art is to propose a new optimum design of a series RL piezoelectric shunt, and at the same time to apply it on a realistic example. For this purpose, a clamped-free steel plate with piezoelectric layers is considered. The laminate structure is excited by using two piezoelectric actuators and it is shunted with two piezoelectric elements. The improvement of damping performance in the presence of structural non-linearities using a non-linear piezoelectric tuned vibration absorber is presented.

Another application of shunt circuits on smart plates is presented in Kim et al. (2000). The measured electrical impedance is the basic parameter for tuning the parameters of passive piezoelectric damping. Unlike the usual tuning method related to a mechanical vibration absorber, the proposed method uses the electrical impedance model of which parameters are found from measured impedance data. Maximization of the amount of dissipated energy at the electrical components is the basic criterion for optimization. Experiments with cantilever beams and plates shows good accordance of the proposed method with the common methods of tuning. The method can be used for structures of any shape and it is also applicable for multiple-mode piezoelectric damping with the same piezoelectric patch.

Last, but not least, in the work of Saravanos (2000) composite beams with piezoceramic patches, piezoelectric plates and laminated piezoelectric shell structures with integrated electric circuits are studied in terms of passive damping. More specifically, numerical and experimental results are presented for several structural formulations. Form the results, the dependence of piezoelectric damping on shunting resistance, structural shape, and curvature is demonstrated. An important outcome, which occurred by both the analytical and experimental studies, was that regardless of the configuration of the structure, the concept of passive piezoelectric damping is feasible and moreover, the values of the electric components can be easily tuned.

\section{OPTIMIZATION OF SHUNT PIEZOELECTRIC SYSTEMS \\ Optimization of the Design and of Placement of PZT}

Optimal placement and dimension optimization of shunted piezoelectric patches for vibration reduction is the object of study in Ducarne et al. (2012). The investigation is carried out through optimization procedures of the damping performance of both the geometry of the piezoelectric patches and their position in the elastic structure. Optimization is based on maximizing the modal electro-mechanical coupling factor (MEMCF) of the mechanical vibration mode on which the shunt is tuned. Several important conclusions regarding the mechanism of coupling between the piezoelectric patches and the host structure are drawn from the study. The results of the investigation are also confirmed experimentally.

In the work of Bachmann et al. (2012a), a strain energy-based finite element approach for the optimum piezoelectric patch positioning is presented. More specifically, the finite element method is used in order to provide an efficient approximation for the calculation of the coupling coefficient. The method is applied on a smart composite turbomachine blade. Two different placement positions of the piezoelectric patches are proposed. An experiment is conducted for the verification of the results on a blade structure and the coupling coefficient was compared to the calculated values. A novel optimization method based on modal strains was used to calculate both electric charge and generalized electromechanical coupling coefficient of piezoelectric patch transducers.

Actuator location optimization is also studied by Foutsitzi et al. (2013b). In this work, a numerical investigation on the optimal voltages and on the optimal placement of piezoelectric actuators for shape control of beam structures is presented. A hybrid optimization scheme, based on great deluge and genetic algorithms, is proposed. The optimal location of the piezoelectric actuators is sought considering the minimization of the error between the achieved and the desired shape of the structure. The results indicate the efficiency of the proposed method.

Last but not least, in the work of Zorić et al. (2012), a multi-objective fuzzy algorithm for the optimization of sizing and location of piezoelectric elements is proposed. Namely, the location of piezoelectric sensors and actuators on thinwalled beam structures is studied. The optimization criterion is the degree of controllability, while the whole process takes into account the involved constraints from the dynamics of the structure. The discretization is done by using the finite element method, while the optimization is based on the particle swarm method.

\section{Optimization of Shunt Characteristics}

In Thomas et al. (2012) the passive damping of vibrations in any form of construction for free and forced oscillation is studied by means of shunted piezoelectric patches. The conclusion from this research is that oscillation reduction performance depends mainly on a single parameter: the so-called modal electromechanical coupling coefficient (MEMCF) of the mechanical vibration mode. Thus, in order to optimally tune the resonant shunt system, one has to find the optimum value of this coefficient. From the experiments, a satisfactory agreement with the proposed theory is achieved.

A new method of adjusting the parameters of shunt circuits for passive piezoelectric damping of structures is presented by Kim et al. (2000). During the adjustment process, the optimal parameters of the shunts are identified from measured impedance data, to maximize the dissipated energy in the shunt circuit.

In Mokrani et al. (2015) a method for the damping of vibrations of structures with piezoelectric transducers is proposed. Specifically, the area near the natural oscillation frequency is studied using an adaptive induction scheme. Linear $\mathrm{RL}$ branches for damping of only one mode at a time have been 
investigated. The problem is associated with the robustness of the RL branch with respect to resonant frequency variability and it was resolved by adapting the inductor value $\mathrm{L}$ through a controlled voltage inducer.

A novel acoustic radiation optimization method for vibrating panel-like structures with passive piezoelectric shunt circuits is presented in Jeon (2009a). The objective of the work is the minimization of the well-radiating modes generated from the panel. The optimization scheme is a mixture of the p-version finite element method, the boundary element method and the particle swarm optimization algorithm. The optimum design works like a stiffener so that well-radiating modes are shifted up. However, the optimized panel require additional damping for attenuating the peak acoustic amplitude, thus a passive shunt damping system is employed. The particle swarm optimization is used in order to achieve the optimum performance for the damping of several modes simultaneously. An experiment is also carried out and it is shown that the numerical results have good agreement with the experimental ones.

In the work of Fleming et al. (2002) a new approach aiming to provide the optimal performance and implementation of piezoelectric circuits is introduced. The method determines the resistance values by minimizing the $\mathrm{H} 2$ standard of the dampened system. The short circuits are normally implemented using discrete resistors, virtual inductors and Riordian gyrators. Synthetic impedance, which consists of a voltage controlled current source and a digital signal processor system, is used to synthesize the ultimate impedance of the shunt network.

In the same direction, the induction requirements of piezoelectric transducers can be reduced by adding capacitors to every piezoelectric circuit as proposed in another work of the same group (Fleming et al., 2003b). The theoretical background is presented and experimentally confirmed for two modes of a simply supported beam.

In Krenk and Høgsberg (2009) an optimal method for the design and the implementation of resonant shunt circuits in structural damping is presented. The resonant control includes a resonant shunt circuit, coupled to the structure via the feedback of a sensor and an actuator. A control system with one degree of freedom is initially investigated, and then the method is expanded to structures with many degrees of freedom. There are several multi-d.o.f. applications which vary from ideal models of piezoelectric sensors-actuators application on beams, to accelerometers-actuators devices on cables. For both cases, near-ideal response characteristics were acquired, when the quasi-static correction of the modal properties was considered.

In Park and Inman (2003) a technique which is able to reduce the amplitude of the structural vibrations by using an electrical passive damper with lower inductance, compared to previous attempts is introduced. To achieve this, a modified and amplified piezoelectric circuit, analyzing the mechanical-electrical analogies has been designed in order to provide the system with natural interpretation. The enhanced shunt circuit demonstrated, both theoretically and experimentally, that the vibration function in the concrete cantilever beam has significantly decreased.
A specific formulation for the tuning of vibration absorbers with shunted piezoelectric transducers, as an alternative to classical tuned mass dampers, is presented in Heuss et al. (2016). The characteristics of the absorber can be altered by applying a purely resistive or a resonant shunt circuit. Moreover, the tuning frequency of the damper can be adapted to the excitation frequency, considering a negative capacitance circuit, which requires only a small amount energy in order to supply the electric components of the shunt system.

In the work of Xie et al. (2014) an electromagnetic shunt damping absorber, based on electromagnetic shunt damping, is employed. The governing equations are enriched with the electromagnetic system. The main parameters of the shunt absorber are obtained by using the particle swarm optimization method. More specifically, the minimization of the response of the variance of system is sought. Both numerical and experimental results which indicate that the electromagnetic shunt damping absorber can reduce significantly the vibrations of the structure are presented.

A balance calibration system for RL piezoelectric shunts is discussed in Høgsberg and Krenk (2015a). The procedure is analytically presented. The proposed balanced calibration scheme with explicit correction for background flexibility present some significant advantages, such as equal modal damping, effective reduction of the dynamic amplification, no overshoot of piezoelectric force amplitude and explicit formulas for the system parameters in terms of structural modal properties and the desired damping ratio.

The optimization of the damping properties of electroviscoelastic objects with external electric circuits is investigated in Matveenko et al. (2015). More specifically, the dynamic characteristics of smart structures with piezoelectric materials are optimized in terms of the resonance frequencies and the damping properties which are provided by external electric shunt circuits which, in turn, incorporate resistance, capacitance and inductance to the system. A natural vibration problem of an electroviscoelastic solid is used for the numerical investigation. Several examples are used in order to demonstrate the efficiency of the proposed method. The shunt circuits can be placed either in series, in parallel, or a combination of them. The advantage of passive piezoelectric damping lies to its capability to tune the damper in a wider frequency range in order to achieve better thermal stability.

A similar study for the optimization of vibration damping for structures with piezoelectric patches, which, however, are shunted with negative capacitance is presented in Wahid et al. (2016). Namely, the ant colony optimization algorithm is used. The frequency range of interest is presented in the context of statistical energy analysis with modal overlap. Two different resistive-negative capacitance (RC) shunt circuits; one in series and one in parallel are studied. The equation of motion is obtained using the Lagrange method, while the ant colony optimization algorithm is used to obtain the optimum values of the shunt circuit for the different frequency areas, for reducing the maximum amount of energy of the vibrating structure.

In Jeon (2009b) another optimization scheme for the improvement of a piezoelectric shunt damping system is 
proposed. The objective of this work is to find the optimal electrical parameters of the shunt circuit for the structural vibration suppression of several modes. The vibration reduction is based on the idea of using the integrated p-version finite element method ( $\mathrm{p}$-version FEM), and the particle swarm optimization algorithm (PSO). The optimal electrical components are determined by the minimization of the objective function, which is given as the sum of the average velocity at a specific frequency range. The performance of the optimal system in terms of structural damping is shown both numerically and experimentally.

A comparative analysis of the electrical circuits used in piezo-electric passive vibration damping is conducted by Caruso (2001). The analysis is carried out by means of analyzing various electrical circuits, i.e., R-L in series, RL in parallel, and RL$\mathrm{C}$ parallel shunt circuits. The optimum values of the electric variables are obtained by using the pole-placement technique, considering the inherent structural damping of the system. Experimental results, in good agreement with the numerical ones, are also reported.

A detailed study of piezoelectric shunts with a parallel resistor and inductor circuit for passive structural damping and vibration control has been made in $\mathrm{Wu}$ (1996). When tuning is optimum, it is easily proved that the peak amplitude of the displacement over the frequency curve of a structural mode decreases with the increase of the shunt resistance. Thus, a "plateau" is created at the area near the optimum resistance. If a further increase of the resistance is considered, the middle of the plateau also decreases, and two peaks appear around the shoulders of the plateau. Structural parameters, such as mass and stiffness, also affect the displacement. When the inductance is larger or smaller than the optimum value, a peak appears on the right or on the left shoulder, respectively.

In the same sense, the optimal electrical circuits for passive vibration damping are sought in Bisegna et al. (2006). In this paper, shunts where an inductance and a capacitance are in parallel and in series with a resistance are proposed. The main focus of the investigation lies on the optimal choice of shunt system to reduce the structural vibrations. An advantage of the proposed modulation is that higher values of the piezoelectric coupling coefficient can be obtained.

In Delpero et al. (2012) a study for the prediction of loss factor in piezoelectric shunt damping, considering the involved electromechanical parameters, is presented. More specifically, an efficient method, which is based on the analysis of the dynamic response of the structure, is proposed for the measurement of the involved coupling coefficient. The method is applied on several structures, with different shunting techniques, i.e., resonant shunts, synchronized switching systems, etc., and the numerical results are compared with the experimental ones.

In Soltani et al. (2014) the optimum tuning rules for piezoelectric shunt control are studied. The piezoelectric transducer is shunted with passive RL electric components for the vibration damping of the host structure. The performance of the proposed method was higher compared to other tuning rules for resonant circuits, even if the improvement of the electromechanical coupling parameters were slight.
Another important aspect, like the minimization of the acoustic radiation of a structure with the use of optimal shunted electrical components with piezoelectric transducers is studied in Collet et al. (2012). The aim of the research was the calculation of the optimal impedance for the reduction of the velocity of the flexural waves. Numerical experiments confirm the proposed method and show the potential for application of the research.

Last but not least, the influence of a digital synthetic impedance on vibration damping applications is studied in Nečásek et al. (2016). The paper presents a compact digital synthetic impedance for application in the field of vibration damping with constructional details. The results of the actual artificial impedance have been compared with several prescribed impedances, resulting in very good performance of the device. An experiment on a one-dimensional spring-mass vibration system, with a piezoelectric actuator incorporated as an interface between the vibration source and vibrating mass, proves the applicability of the proposed model.

\section{APPLICATIONS OF SHUNT PIEZOELECTRIC CIRCUITS}

In Kurczyk and Pawelczyk (2016) a shunt circuit with a single piezoelectric transducer and a suitably defined fuzzy system is considered for the noise control of structures. More specifically, a fuzzy inference system is used to adapt the parameters of the electrical circuit. For the optimization of the fuzzy rules, a genetic algorithm is used. The numerical results indicate the efficiency of the method, which is useful for several industrial applications.

Another application of the shunt damping is on the vibration control of hard drives. More specifically, in Lim and Choi (2007) a piezoelectric bimorph shunt damping circuit is used. In the first part of this work, the dynamic analysis and modeling of the system is described. A target vibration mode which significantly restricts the density increment of the hard drive is determined by undertaking both modal testing and finite element analysis tools. For the control of unwanted oscillations, a piezoelectric bimorph is designed and integrated into the system. The mechanical impedance here is derived from the lamination theory and the linear piezoelectric constitutive equations, while the coupling coefficient is incorporated into this impedance. From the numerical results it is shown that the displacement transmissibility can be tuned by adjusting only the coupling coefficient. This implies that the total vibration of the system can be suppressed successfully by activating the piezoelectric shunt circuits which are proposed.

A reduced-order finite element model of double sandwich panels using shunted piezoelectric patches for noise and vibration reduction is developed and presented in Larbi et al. (2016). The paper deals with the suppression of sound transmission through double laminated sandwich panels of three layers each, with viscoelastic core and an air cavity between the layers. A semi-passive piezoelectric shunt technique with resonant circuits is used for the damping of vibrations of specific resonance frequencies of the resulted coupled system. Both a full- and a reduced- order finite element formulation of 
the visco-electro-mechanical acoustic system, which takes into account the frequency dependence of the viscoelastic material is presented. More specifically, the coupled system is solved considering the first real short-circuit structural modes, while a static correction is introduced in order to consider the effect of higher eigenmodes. The efficiency of the proposed scheme is illustrated by several results.

A three-hinged arch controlled by piezoelectric stack actuators and passive RL electrical circuits is presented in Pagnini and Piccardo (2016). The proposed system is considered as a simple structural model, which can be used as an ignition in order to generalize to more common civil and industrial engineering structures. The Lagrangian approach is used for the formulation, taking into account the analogy between the electrical and the mechanical model, which can guarantee multimodal attenuation. Some preliminary results, which indicate the efficiency of the method, are also presented.

An adaptive control strategy based on passive piezoelectric shunt techniques with application to mistuned bladed disks is described in Zhou et al. (2013). Resonant shunted piezoelectric transducers are placed onto the disk between adjacent blades in order to reduce the vibrations of the blade, via the blade-disk coupling. In this study, piezoelectric damping is exploited with the objective of minimizing the blade mistuning effects using genetic algorithms. Numerical experiments indicate that a good performance is achieved.

The self-excited vibration called chatter is a problem which recurs during machining. Passive shunt circuits can increase the system's damping and thus, they can be used to control chatter. In Venter and da Silva (2016) and Venter et al. (2015), a method for reducing chatter in turning using a piezoelectric LR passive shunt strategy is proposed. Firstly, the system is evaluated without any control strategy. Then, LR passive shunts are used in the two main directions of vibration, and the response of the system is analyzed. The electromechanical coupled structure which is considered in the numerical simulations presents FRFs that are very close the experiments. Moreover, the robustness of the passive shunt control strategy for chatter reduction is discussed in Venter and da Silva (2016). Two different boundary conditions formulations are tested experimentally, and the effectiveness of the passive control strategy is shown. The results indicate the lack of robustness of the method, due to its inability to perform well for both conditions, however the damping is increased for the first experiment, where the fixation was selected in a form that the system could maintain its natural frequency.

An application on helicopter rotor blade vibration control on the basis of active/passive piezoelectric dampers is presented in Shevtsov et al. (2009). More specifically, a comparative analysis on the efficiency of the helicopter rotor blades vibration suppression was conducted both by active controlled and passive shunted piezoelectric patches. The obtained results illustrate the efficiency of the proposed method.

A passive damping of composite blades using embedded piezoelectric shunt modules is proposed in Bachmann et al. (2012b). Namely, the potential improvement of the mechanical damping of composite fan blades is sought by using two different passive damping techniques; piezoelectric shunt circuits and shape memory allow wires. From the results of the investigation, both piezoelectric shunt and shape memory alloy damping were effective in terms of passive damping for the application in open rotor fan blade applications.

The vibration damping of turbomachinery components with RL-shunted piezoelectric transducers is discussed in Mokrani et al. (2012). A design rule, capable of overcoming the high level of uncertainties, is given for the RL-shunt circuits. The performance of the proposed schemes is validated through experiments. The results indicate the simplicity, the efficiency and the robustness of the whole system. An application of piezoelectric shunt damping on circular saw blades with autonomous power supply for noise and vibration reduction is presented in Pohl and Rose (2016). Due to the thin blade and the contact of the cutting edges, circular saws suffer of vibrations and tension phenomena, thus a novel damping concept is proposed. The experimental investigation indicates a significant attenuation of the vibration amplitude over a wide range of frequencies when the system is not rotating. In the rotating condition the damping which is achieved is lower and it is limited to a narrower band.

The investigation of Min et al. (2010) focuses on the efficiency of a piezoelectric shunt vibration control of turbine blades, especially for a centrifugal rotation state. Piezoelectric patches are placed on plate specimens and two types of circuits, resistive $\mathrm{R}$ circuits and resonant $\mathrm{RL}$ circuits are used for testing. The experiments and the analyses are executed both in spinning and in non-spinning conditions. The results show the ability of shunted piezoelectric damping to suppress vibrations under centrifugal loading of turbine blades.

The shunt vibration technology was applied in Kurczyk and Pawełczyk (2018) for noise control. The aim of study was to reduce the noise which comes from outside, by damping vibration control of structures. The control vibration of walls achieved with the use of neural networks. An experimental simulation was carried out to confirm the proposed method.

The use of piezoelectric materials in combination with RL shunt circuits is investigated in Min et al. (2008). The main purpose of study was to reduce the problems of high cycle fatigue (HCF) in of turbomachinery blades which caused from vibrations. Experiments on resonant damping control with shunted piezoelectric elements with passive and active control techniques have shown that the optimal electrical components reduce significantly the vibrations.

In Rana et al. (2013) an observer-based model predictive control (OMPC) scheme is investigated in order to improve the positioning of an Atomic Force Microscope. The design of the control system takes into account the piezoelectric tube scanner (PTS) model. For the consideration of the full-state properties, a Kalman filter is used. Experimental results indicate the efficiency of the control method.

Another application of piezoelectric shunt control is discussed in Fairbairn et al. (2011). The aim of the research was the improvement of the image quality and scan rate of tapping mode Atomic Force Microscopy (AFM). The scan rate is ameliorated by degreasing the quality factor of the microcantilever, and the PZT shunt control is applied by using an electrical impedance in series with the cantilever tip 
oscillation circuit. The conducted experiment indicates the efficiency of the proposed method in scan rate and image quality improvement.

The electrical control of elasticity with piezoelectric coupling is investigated in Date et al. (2000). When shunt circuits are connected in parallel with a piezoelectric polymer film, the dynamic elastic constant increases. Many separate electrical circuits (resistance, inductance and capacitance circuit) can be used for the measurement of the influence in the elastic constant. Experimental tests of the dynamic elastic constants validate the theoretical model. The results of the research have a particular contribution on sound absorption.

An application of shunt vibration damping is presented in Takigami and Tomioka (2005). More specifically, stationary excitation tests are carried out over a railway passenger vehicle car body for vibration control using piezoelectric transducers with shunt circuits. The experiments were conducted for different types of shunts, and the results indicate the deterioration of frequency response gain between excitation force and acceleration on the floor at the natural frequency, up to about $30 \%$. In a similar investigation of the same group (Takigami and Tomioka, 2008), the suppression of bending vibrations of a $5 \mathrm{~m}$ long Shinkansen railway vehicle carbody with small piezoelectric transducers and shunt circuits is studied. The results indicate that the vibrations can be successfully reduced.

\section{ENERGY HARVESTING WITH SHUNT CIRCUITS}

A parametric study on a collocated piezoelectric beam vibration absorber and power harvester is conducted in Huang et al. (2016). More specifically, the parametric effects of a piezoelectric beam which is used both as a vibration absorber and a power harvester are investigated. A load resistance which increases with the lumped mass ratio is used in order to harvest the maximum amount of power. Experimental results have proved the existence of a best value for the resistance, however the measured harvested power values were lower than the theoretical ones, due to structural damping and possible divergence of material properties.

A novel electromagnetic resonant shunt tuned massdamper-inerter with application on wind induced vibration control of building structures and energy harvesting is proposed in Luo et al. (2017). A single degree of freedom system is considered for the study of the performance of the damper. The effectiveness and the robustness of the proposed technique in both the frequency and time domain are shown by the numerical results.

Moreover, the effect of shunted piezoelectric control for the fine-tuning of piezoelectric power harvesters is studied in Lumentut and Howard (2015). Namely, a novel analytical technique on the modeling of shunt circuit control responses for the modification of the electromechanical piezoelectric harvesting structures is presented. The proposed technique presents self-adaptive capabilities in terms of harvesting response, for the adjustment of the frequency band, as well as of the power amplitude of the harvesting devices.

The optimization of piezoelectric energy harvesting devices in order to achieve advanced electromechanical efficiency and frequency range is discussed in Godoy et al. (2014). More specifically, some preliminary results on the topological optimization of the piezoelectric layer which is bonded to a sliding-free plate and connected to shunt circuit are presented. From the obtained results, one concludes that topology optimization of active layers can significantly increase efficiency of the system in terms of the amount of the energy which is harvested per unit mass.

An energy harvesting system for the power supply of a shunt piezoelectric system, i.e., to achieve zero energy consumption have been proposed by Tairidis et al. (2018). The shunt system is developed for the suppression of vibrations of smart structures and it usually needs a small amount of energy in order to operate. Energy harvesting can be proved very effective in this direction. In the method which is proposed by the authors, the whole implementation will be restricted only to the collection of the necessary amount of energy in order to make the system selfsustained.

\section{CONCLUSIONS}

Shunt piezoelectric systems have been extensively used for vibration and noise control during the last several years. In fact, resonant shunts are proved to be very efficient and stable for the reduction of vibration on smart piezoelectric structures, such as beams and plates. Moreover, it is proven that if the values of the electrical parameters (e.g., of the inductance, the resistance etc.) are tuned properly, a minimum number of piezoelectric patches can be sufficient. In this direction, the optimization of shunt parameters has also been an object of study in the current state of the art, either for single-mode, as well as for multi-mode shunt circuits as presented in the present review.

From the numerous applications which are reviewed in the present paper, it is clear, as well, that shunt piezoelectric systems can be very effective for several different purposes such as among others, the control of vibrations on hard drives, the noise reduction on acoustic applications, the improvement of the image quality and scan rate of tapping mode Atomic Force Microscopy and so on and so forth.

An interesting idea for further investigation is the extension of the use of Riordian gyrators, as they could possibly solve the problem of large capacitors which are needed in such systems. Moreover, adaptive and/or fuzzy controlled shunt systems as described in Tairidis (in press) should be studied further. Last but not least, shunted piezoelectric systems can be used for the fine-tuning of piezoelectric power harvesters as seen in Tairidis et al. (2018), which is 
very important in the direction of designing zero energy consumption systems.

\section{AUTHOR CONTRIBUTIONS}

KM did the investigation in the framework of the preparation of his Ph.D. Thesis. GT and GS supervised the work. GT and PK supported the research work and provided with practical help.

\section{FUNDING}

(6) H.F.R.I. Hellenic Foundation for Research and Innovation (HFRI) and

\section{REFERENCES}

Albareda, A., and Pérez, R. (2011). "Non-linear behaviour of piezoelectric ceramics." in Multifunctional Polycrystalline Ferroelectric Materials. Springer Series in Materials Science, eds L. Pardo and J. Ricote (Dordrecht: Springer). 681-726. doi: 10.1007/978-90-481-2875-4_15

American National Standards Institute, IEEE Ultrasonics Ferroelectrics and Frequency Control Society, Standards Committee, and Institute of Electrical and Electronics Engineers (1987). IEEE Standard on Piezoelectricity: An American National Standard. New York, NY: Institute of Electrical and Electronics Engineers

Andreaus, U., and Porfiri, M. (2007). Effect of electrical uncertainties on resonant piezoelectric shunting. J. Intell. Material Syst. Struct. 18, 477-485. doi: 10.1177/1045389X06067116

Bachmann, F., Bergamini, A. E., and Ermanni, P. (2012a). Optimum piezoelectric patch positioning: a strain energy-based finite element approach. J. Intell. Material Syst. Struct. 23, 1575-1591. doi: 10.1177/1045389X12447985

Bachmann, F., Oliveira, R., Sigg, A., Schnyder, V., Delpero, T., Jaehne, R., et al. (2012b). Passive damping of composite blades using embedded piezoelectric modules or shape memory alloy wires: a comparative study. Smart Mater. Struct. 21:075027. doi: 10.1088/0964-1726/21/7/075027

Behrens, S., Fleming, A. J., and Moheimani, S. O. (2004). "Control Orientated Synthesis of Electromagnetic Shunt Impedances for Vibration Isolation," in 3rd IFAC Symposium on Mechatronic Systems 2004 (Sydney), 301-306. doi: 10.1016/S1474-6670(17)31120-5

Benjeddou, A. (2018). Field-dependent nonlinear piezoelectricity: a focused review. Int. J. Smart Nano Mater. 9, 68-84 doi: 10.1080/19475411.2018.1439850

Berardengo, M., Cigada, A., Manzoni, S., and Vanali, M. (2015). Vibration control by means of piezoelectric actuators shunted with $1 \mathrm{r}$ impedances: performance and robustness analysis. Shock Vib. 2015:704265. doi: 10.1155/2015/704265

Berardengo, M., Manzoni, S., and Conti, A. M. (2017). Multi-mode passive piezoelectric shun tdamping by means of matrix in equalities. J. Sound Vib. 405, 287-305. doi: 10.1016/j.jsv.2017.06.002

Bisegna, P., Caruso, G., and Maceri, F. (2006). "On the choice of the shunt circuit for single-mode vibration damping of piezoactuated structures," in Mechanical Modelling and Computational Issues in Civil Engineering. eds M. Frémond, and F. Maceri, (Berlin: Springer), (389-400). doi: 10.1007/3-540-32399-6_24

Buchacz, A., and Płaczek, M. (2011). Mechatronic system with shunted piezoelectric damper modelled with structural damping. Proc. Appl. Mathemat. Mech. 11, 261-262. doi: 10.1002/pamm.201110122

Buchacz, A., Płaczek, M., and Wróbel, A. (2013). Control of characteristics of mechatronic systems using piezoelectric materials. J. Theor. App. MechPol. 51, 225-234. Available online at: http://www.ptmts.org.pl/jtam/index.php/ jtam/article/view/v51n1p225

Caruso, G. (2001). A critical analysis of electric shunt circuits employed in piezoelectric passive vibration damping. Smart Mater. Struct. 10, 1059-1068. doi: 10.1088/0964-1726/10/5/322

Chen, Y.-Y., Vasic, D., Costa, F., Lee, C.-K., and Wu, W.-J. (2013). Self-powered semi-passive piezoelectric structural damping based on zero-velocity crossing detection. Smart Mater. Struct. 22:025029. doi: 10.1088/0964-1726/22/2/025029 the General Secretariat for Research and Technology (GSRT), under the HFRI Ph.D. Fellowship grant (GA. no. 34254).

\section{ACKNOWLEDGMENTS}

GT gratefully acknowledges the French Embassy in Greece and the French Government for the funding of his visit to the Structural Mechanics and Coupled Systems Laboratory of the institute Conservatoire national des arts et métiers though a fellowship of the program Séjours scientifiques de haut niveau for new researchers. He would also like to express his sincere gratitude to Prof. Jean-François Deü and Prof. Roger Ohayon for the hospitality at the Institute and the fruitful cooperation.

Cheng, T. H., Wang, X. L., and Oh, I. K. (2009). "Electromagnetic multimode shunt damper for flexible beams based on current flowing circuit," in Proceeding SPIE 7493, Second International Conference on Smart Materials and Nanotechnology in Engineering (Weihai). doi: 10.1117/12.843409

Chevallier, G., Ghorbel, S., and Benjeddou, A. (2009). Piezoceramic shunted damping concept: testing, modelling and correlation. Mec. Ind. 10, 397-411. doi: $10.1051 / \mathrm{meca} / 2009073$

Collet, M., Ouisse, M., Ichchou, M. N., and Ohayon, R. (2012). Semiactive optimization of $2 \mathrm{D}$ wave dispersion into shunted piezo-composite systems for controlling acoustic interaction. Smart Mater. Struct. 21:094002. doi: 10.1088/0964-1726/21/9/094002

Collinger, J. C., Wickert, J. A., and Corr, L. R. (2009). Adaptive piezoelectric vibration control with synchronized switching. J. Dyn. Syst. Meas Control. 131:041006. doi: 10.1115/1.3117189

Corr, L., and Clark, W. (2003). A novel semi-active multi-modal vibration control law for a piezoceramic actuator. J. Vib. Acoust. 125, 214-222. doi: 10.1115/1.1547682

Curie, P., and Curie, J. (1881). Contractions et dilations produits par des tensions electriques dans les cristeaux hemieedres a faces inclines. Comptes Rendus de l' Acad. Sci. 93, 1137-1140.

Date, M., Kutani, M., and Sakai, S. (2000). Electrically controlled elasticity utilizing piezoelectric coupling. J. Appl. Phys. 87, 863-868. doi: 10.1063/1.371954

Delpero, T., Bergamini, A. E., and Paolo, E. (2012). Identification of electromechanical parameters in piezoelectric shunt damping and loss factor prediction. J. Intell. Material Syst. Struct. 24, 287-298. doi: 10.1177/1045389X12457253

Deü, J.-F., Larbi, W., Ohayon, R., and Sampaio, R. (2014). Piezoelectric shunt vibration damping of structural-acoustic systems: finite element formulation and reduced-order model. J. Vib. Acoust. 136:031007. doi: 10.1115/1.40 27133

Ducarne, J., Thomas, O., and Deü, J.-F. (2010). Structural vibration reduction by swith shunting of piezoelectric elements: modelling and optimization. J. Intell. Material Syst. Struct. 21, 797-816. doi: 10.1177/1045389X10367835

Ducarne, J., Thomas, O., and Deü, J.-F. (2012). Placement and dimension optimization of shunted piezoelectric patches for vibration reduction. J. Sound Vib. 331, 3286-3303. doi: 10.1016/j.jsv.2012.03.002

Fairbairn, M. W., Moheimani, S. O., and Fleming, A. J. (2011). "Improving the scan rate and image quality in tapping mode atomic force microscopy with piezoelectric shunt control, in Australian Control Conference (Melbourne), 26-31.

Fleming, A., Behrens, S., and Moheimani, S. (2000). "A new approach to piezoelectric shunt damping," in Proceeding International Symposium on Smart Structures and Microsystems (Hong Kong).

Fleming, A., Behrens, S., and Moheimani, S. (2002). Optimization and implementation of multimode piezoelectric shunt damping systems. IEEE/ASME T Mech. 7, 87-94. doi: 10.1109/3516.990891

Fleming, A., and Moheimani, S. (2004). Improved current and charge amplifiers for driving piezoelectric loads, and issues in signal processing design for synthesis of shunt damping circuits. J. Intell. Material Syst. Struct. 15, 77-92. doi: $10.1177 / 1045389 X 04039701$ 
Fleming, A. J., Behrens, S., and Moheimani, S. O. (2003a). "An Autonomous Piezoelectric Shunt Damping System. In Proceedings Smart Structures and Materials 2003: Damping and Isolation (San Diego).

Fleming, A. J., Behrens, S., and Moheimani, S. O. (2003b). Reducing the inductance requirements of piezoelectric shunt damping systems. Smart Mater. Struct. 12, 57-64. doi: 10.1088/0964-1726/12/1/307

Fleming, A. J., and Moheimani, S. O. (2005). Control orientated synthesis of highperformance piezoelectric shunt impedances for structural vibration control. IEEE T-CST. 13, 98-112. doi: 10.1109/TCST.2004.838547

Forward, R. L. (1979). Electronic damping of vibrations in optical structures. Appl. Opt. 18, 690-697. doi: 10.1364/AO.18.000690

Forward, R. L., and Swigert, C. J. (1981). Electronic damping of orthogonal bending modes in a cylindrical mast-experiment. J. Spacecr Rock. 18, 5-10. doi: $10.2514 / 3.28048$

Foutsitzi, G. A., Gogos, C. G., Hadjigeorgiou, E. P., and Stavroulakis, G. E. (2013b). Actuator location and voltages optimization for shape control of smart beams using genetic algorithms. Act 2, 111-128. doi: 10.3390/act2040111

Giorgio, I., Culla, A., and Vescovo, D. D. (2009). Multimode vibration control using several piezoelectric transducers shunted with a multiterminal network. Arc. Appl. Mech. 79, 859-879. doi: 10.1007/s00419-008-0258-x

Godoy, T. C., Trindade, M. A., and Deü, J.-F. (2014). “Topological optimization of piezoelectric energy harvesting devices for improved electromechanical efficiency and frequency range," in 10th World Congress on Computational Mechanics (São Paulo), 4003-4016. doi: 10.5151/meceng-wccm2012-19664

Goldstein, A. L. (2011). Self-Tuning multimodal piezoelectric shunt damping. J. Braz. Soc. Mech. Sci. Eng. 33, 428-436. doi: 10.1590/S1678-58782011000400006

Granier, J. J., Hundhausen, R. J., and Gaytad, G. E. (2002). "Passive modal damping with piezoelectric shunts," in The 20th International Modal Analysis Conference (Los Angeles).

Hagood, N., and von Flotow, A. (1991). Damping of structural vibrations with piezoelectric materials and passive electrical networks. J. Sound Vib. 146, 243-268. doi: 10.1016/0022-460X(91)90762-9

Hassan, H., Yves, B., and Razek, A. (2011). "Finite element model of a beam structure with piezoelectric patches using RL shunt circuits," in 14th International Conference on Active Systems for Dynamics Markets (Darmstadt), (124-131).

Heuss, O., Salloum, R., Mayer, D., and Melz, T. (2016). Tuning of a vibration absorber with shunted piezoelectric transducers. Arch. Appl. Mech. 86, 1715-1732. doi: 10.1007/s00419-014-0972-5

Høgsberg, J., and Krenk, S. (2015a). Balanced calibration of resonant piezoelectric RL shunts with quasi-static background flexibility correction. J. Sound Vib. 341, 16-30. doi: 10.1016/j.jsv.2014.12.006

Høgsberg, J., and Krenk, S. (2015b). "Piezoelectric RL shunt damping of flexible structures," in 7th ECCOMAS Thematic Conference on Smart Structures and Materials. (Ponta Delgada).

Hollkamp, J. J. (1994). Multimodal passive vibration suppression with piezoelectric materials and resonant shunts. J. Intel. Mat. Syst Str. 5, 49-57. doi: 10.1177/1045389X9400500106

Huang, S.-C., Tsai, C.-Y., and Liao, H.-H. (2016). Parametric study on a collocated PZT beam vibration absorber and power harvester. J. Mech. Sci. Technol. 30, 4877-4885. doi: 10.1007/s12206-016-1006-8

Isola, F., d., Maurini, C., and Porfiri, M. (2004). Passive damping of beam vibrations through distributed electric networks and piezoelectric transducers: prototype design and experimental validation. Smart Mater. Struct. 13, 299-308. doi: 10.1088/0964-1726/13/2/008

Jeon, J.-Y. (2009a). Passive acoustic radiation control for a vibrating panel with piezoelectric shunt damping circuit using particle swarm optimization algorithm. J. Mech. Sci. Technol. 23, 1446-1455. doi: 10.1007/s12206-009-0349-9

Jeon, J.-Y. (2009b). Passive vibration damping enhancement of piezoelectric shunt damping system using optimization approach. J. Mech. Sci. Technol. 23, 1435-1445. doi: 10.1007/s12206-009-0402-8

Joshi, S. P. (1992). Non-linear constitutive relations for piezoceramic materials, Smart Mater. Struct. 1, 80-83 doi: 10.1088/0964-1726/1/1/012

Kim, J., Ryu, Y.-H., and Choi, S.-B. (2000). New shunting parameter tuning method for piezoelectric damping based on measured electrical impedance. Smart Mater. Struct. 9, 868-877. doi: 10.1088/0964-1726/9/6/318

Krenk, S., and Høgsberg, J. (2009). Optimal resonant control of flexible structures. J. Sound Vib. 323, 530-554. doi: 10.1016/j.jsv.2009.01.031
Kurczyk, S., and Pawelczyk, M. (2016). "Structural noise control using a shunt circuit with single piezoelectric transducer and fuzzy algorithm," in The 23rd International Congress on Sound and Vibration (Athens).

Kurczyk, S., and Pawełczyk, M. (2018). Nonlinear structural acoustic control with shunt circuit governed by a soft-computing algorithm. Arch. Acoust. 43, 397-402. doi: 10.24425/123911

Larbi, W., Deü, J.-F., and Ohayon, R. (2016). Finite element reduced order model for noise and vibration reduction of double sandwich panels using shunted piezoelectric patches. Appl. Acoust. 108, 40-49. doi: 10.1016/j.apacoust.2015.08.021

Lim, S. C., and Choi, S. B. (2007). Vibration control of an HDD disk-spindle system utilizing piezoelectric bimorph shunt damping: I. dynamic analysis and modeling of the shunted drive. Smart Mater. Struct. 16, 891-900. doi: 10.1088/0964-1726/16/3/039

Lippmann, G. (1881). Principe de la conservation de l'électricité (Principle of the conservation of electricity). Ann. de Chimie et de Physique. 24:145. doi: 10.1038/024140b0

Liu, Y.-P., and Vasic, D. (2013). semi-passive piezoelectric structural damping based on a pulse-width modulation switching circuit. J. Mech. Sci. Technol. 27, 1-9. doi: 10.1007/s12206-013-0906-0

Lossouarn, B., Aucejo, M., Deü, J.-F., and Multon, B. (2017). Design of inductors with high inductance values for resonant piezoelectric damping. Sens. Actuator A-Phys. 259, 68-76. doi: 10.1016/j.sna.2017.03.030

Lumentut, M. F., and Howard, I. M. (2015). Effect of shunted piezoelectric control for tuning piezoelectric power harvesting system responses-analytical techniques. Smart Mater. Struct. 24:105029. doi: 10.1088/0964-1726/24/10/105029

Luo, Y., Sun, H., Wang, X., Zuo, L., and Chen, N. (2017). Wind induced vibration control and energy harvesting of electromagnetic resonant shunt tuned mass-damper-inerter for building structures. Shock Vib. 2017:4180134. doi: $10.1155 / 2017 / 4180134$

Mack, O. (2003). "The non-linearity of piezoelectric force transducers and their analytical modelling," in Proceedings, XVII IMEKO World Congress (Dubrovnik).

Marneffe, B., de, and Preumont, A. (2008). Vibration damping with negative capacitance shunts: theory and experiment. Smart Mater. Struct. 17:035015. doi: 10.1088/0964-1726/17/3/035015

Matveenko, V. P., Yurlov, M. A., and Yurlova, N. A. (2015). “Optimization of the damping properties of electro-viscoelastic objects with external electric circuits," in Mechanics of Advanced Materials, eds V. V Silberschmidt, and V.P Matveenko (Cham: Springer), 79-100. doi: 10.1007/978-3-319-17118-0_4

McDaid, A. J., and Mace, B. R. (2016). A robust adaptive tuned vibration absorber using semi-passive shunt electronics. IEEE Trans. Ind. Electron. 63, 5069-5077. doi: 10.1109/TIE.2016.2554541

Min, J. B., Duffy, K. P., Choi, B. B., Morrison, C. R., Jansen, R. H., and Provenza, A. J. (2008). "A resonant damping study using piezoelectric materials," in 49th AIAA/ASME/ASCE/AHS/ASC Structures, Structural Dynamics, and Materials (Schaumburg). doi: 10.2514/6.2008-2335

Min, J. B., Duffy, K. P., and Provenza, A. J. (2010). "Shunted piezoelectric vibration damping analysis including centrifugal loading effects," in Structural Dynamics and Materials Conference (Orlando), 2716. doi: 10.2514/6.2010-2716

Moheimani, R. S., and Fleming, A. J. (2006). Piezoelectric Transducers for Vibration Control and Damping. London: Springer-Verlag.

Mokrani, B., Bastaits, R., Viguié, R., and Preumont, A. (2012). "Vibration damping of turbomachinery components with piezoelectric transducers: Theory and Experiment," in International Conference on Noise and Vibration Engineering, Proceedings of ISMA 2012 (Leuven), 345-356.

Mokrani, B., Burda, I., Tian, Z., and Preumont, A. (2015). "Uncertainty, adaptive inductor for vibration damping in presence of uncertainty," in 7th ECCOMAS Thematic Conference on Smart Structures and Materials (Ponta Delgada).

Mukherjee, B. K., Ren, W., Liu, S.-F., Masys, A. J., and Yang, G. (2001). "Nonlinear properties of piezoelectric ceramics," in Smart Structures and Materials 2001: Active Materials: Behavior and Mechanics, Proceedings of SPIE, ed C. S. Lynch (Newport Beach, CA). doi: 10.1117/12.432738

Nečásek, J., Václavík, J., and Marton, P. (2016). Digital synthetic impedance for application in vibration damping. Rev. Sci. Instrum. 87:024704. doi: $10.1063 / 1.4942085$

Nguyen, C., and Pietrzko, S. (2006). "FE analysis of a PZT-actuated adaptive beam with vibration damping using an electric multiple-mode shunt system," 
in International Conference on Noise and Vibration Engineering, Proceedings of ISMA 2006 (Leuven), 461-472.

Niederberger, D. (2005). "Design of optimal autonomous switching circuits to suppress mechanical vibration hybrid systems: computation and control,"in 8th International Workshop, HSCC 2005 (Zurich), 511-525. doi: 10.1007/978-3-540-31954-2_33

Niederberger, D., Fleming, A., Moheimani, S. O., and Morari, M. (2004). “Onlinetuned multi-mode resonant piezoelectric shunt for broadband vibration suppression," in 3rd IFAC Symposium on Mechatronic Systems 2004 (Sydney), 37, 295-300. doi: 10.1016/S1474-6670(17)31119-9

Niederberger, D., and Morari, M. (2006). An autonomous shunt circuit for vibration damping. Smart Mater. Struct, 15, 359-364. doi: 10.1088/0964-1726/15/2/016

Pagnini, L. C., and Piccardo, G. (2016). The three-hinged arch as an example of piezomechanic passive controlled structure. Continu. Mech Therm. 28, 1247-1262. doi: 10.1007/s00161-015-0474-x

Park, C. H., and Inman, D. J. (2003). Enhanced piezoelectric shunt design. Shock Vib. 10, 127-133. doi: 10.1155/2003/863252

Park, C. H., Kim, Y. H., and Park, H. C. (2005). Dynamic formulations of plates with shunted piezoelectric materials. J. Intel. Mater. Syst. Struct. 16, 971-976. doi: 10.1177/1045389X05053781

Park, C. H., and Park, H. C. (2003). Multiple-mode structural vibration control using negative capacitive shunt damping. J. Mech. Sci. Technol. 17, 1650-1658. doi: 10.1007/BF02983594

Pohl, M., and Rose, M. (2016). Piezoelectric shunt damping of a circular saw blade with autonomous power supply for noise and vibration reduction. J. Sound Vib. 361, 20-31. doi: 10.1016/j.jsv.2015.09.021

Preumont, A. (2006). Mechatronics Dynamics of Electromechanical and Piezoelectric Systems. Solid Mechanics and Its Applications. Cham: Springer.

Preumont, A. (2018). Vibration Control of Active Structures. Solid Mechanics and Its Applications. Cham: Springer.

Rana, M. S., Pota, H. R., and Petersen, I. R. (2013). "Advanced control of atomic force microscope for faster image scanning," in Applied Methods and Techniques for Mechatronic Systems, eds L. Liu, Q. Zhu, L. Cheng, Y. Wang, and D. Zhao (Berlin; Heidelberg: Springer), 371-388. doi: 10.1007/978-3-642-36385-6_19

Saravanos, D. (1999). Damped vibration of composite plates with passive piezoelectric-resistor elements. J. Sound Vib. 221, 867-885. doi: 10.1006/jsvi.1998.2037

Saravanos, D. (2000). Passively damped laminated piezoelectric shell structures with integrated electric networks. AIAA J. 38, 1260-1268. doi: 10.2514/2.1096

Schoeftner, J., and Irschik, H. (2009). Passive damping and exact annihilation of vibrations of beams using shaped piezoelectric layers and tuned inductive networks. Smart Mater. Struct. 18:125008. doi: 10.1088/0964-1726/18/12/125008

Schoeftner, J., and Irschik, H. (2011). A comparative study of smart passive piezoelectric structures interacting with electric networks: Timoshenko beam theory versus finite element plane stress calculations. Smart Mater. Struct. 20:025007. doi: 10.1088/0964-1726/20/2/025007

Shevtsov, S., Soloviev, A., Acopyan, V., and Samochenko, I. (2009). "Helicopter rotor blade vibration control on the basis of active/passive piezoelectric damping approach," in PHYSCON (Catania).

Silva, L., Deü, J.-F., Larbi, W., and Trindade, M. (2014). “An efficient finite element approach for reduction of structural vibration and acoustic radiation by passive shunted piezoelectric systems," in 10th World Congress on Computational Mechanics (Sao Paulo: Blucher Mechanical Engineering Proceedings).

Soltani, P., Kerschen, G., Tondreau, G., and Deraemaeker, A. (2014). Piezoelectric vibration damping using. Smart Mater. Struct. 23:125014. doi: 10.1088/0964-1726/23/12/125014

Stavroulakis, G., Foutsitzi, G., Hadjigeorgiou, E., Marinova, D., and Baniotopoulos, C. (2005). Design and robust optimal control of smart beams with application on vibrations suppression. Adv. Eng. Softw. 36, 806-813. doi: 10.1016/j.advengsoft.2005.03.024

Tairidis, G. K. (in press). Vibration control of smart composite structures using shunted piezoelectric systems and neuro-fuzzy techniques. J. Vib. Control.

Tairidis, G. K., Marakakis, K., Koutsianitis, P., Foutsitzi, G., Stavroulakis, G. E., Deü, J.-F., et al. (2018). "Energy harvesting system for the power supply of a shunt piezoelectric system developed for vibration suppression," in Proceedings of the international conference on wind energy harvesting (Catanzaro Lido), 223-227.

Takigami, T., and Tomioka, T. (2005). Investigation to suppress bending vibration of railway vehicle carbodies using piezoelectric elements. Q. Rep. RTRI 46, 225-230. doi: 10.2219/rtriqr.46.225

Takigami, T., and Tomioka, T. (2008). Bending vibration suppression of railway vehicle carbody with piezoelectric elements. J. Mech. Syst. Transp. Logist. 1, 111-121. doi: 10.1299/jmtl.1.111

Thomas, O., Deü, J.-F., and Ducarne, J. (2009). Vibrations of an elastic structure with shunted piezoelectric patches: efficient finite element formulation and electromechanical coupling coefficients. Int. J. Numer Meth. Eng. 80, 235-268. doi: $10.1002 /$ nme.2632

Thomas, O., Ducarne, J., and Deu, J.-F. (2012). Performance of piezoelectric shunts for vibration reduction. Smart Mater. Struct. 21:015008. doi: 10.1088/0964-1726/21/1/015008

Tondreau, G., Soltani, P., and Kerschen, G. (2014). "Electrical tuned vibration absorber: application of the equal-peak method to linear and non-linear RL piezoelectric shunts," in 25nd International Conference on Adaptive Structures and Technologies (Hague).

Trindade, M. A., and Maio, C. E. (2008). Multimodal passive vibration control of sandwich beams with shunted shear piezoelectric materials. Smart Mater. Struct. 17:055015. doi: 10.1088/0964-1726/17/5/055015

Venter, G. S., and da Silva, M. M. (2016). "On the robustness of the passive shunt control strategy for chatter reduction," in International Conference of Noise and Vibration Engineering (Curitiba), 3721-3734.

Venter, G. S., Missura, L., and da Silva, M. M. (2015). "Reducing chatter in turning using a piezoelectric LR passive shunt strategy," in $23 r d$ ABCM International Congress of Mechanical Engineering (Rio de Janeiro).

Viana, F. A., and Steffen, J. V. (2006). Multimodal vibration damping through piezoelectric patches and optimal resonant shunt circuits. J. Braz. Soc. Mech. Sci. Eng. 28, 293-310. doi: 10.1590/S1678-58782006000300007

Wahid, A. N., Muthalif, A. G., and Nor, K. A. (2016). Investigating negative capacitance shunt circuit for broadband vibration damping and utilizing ACO for optimization. Int. J. Circuits Electron. 1, 168-173. Available online at: https://www.iaras.org/iaras/journals/computer-science-communications/ caijce/investigating-negative-capacitance-shunt-circuit-for-broadbandvibration-damping-and-utilizing-aco-for-optimization

Wu, S.-Y. (1996). "Piezoelectric shunts with a parallel R-L circuit for structural damping and vibration control," in Symposium on Smart Structures and Materials (San Diego), 259-269. doi: 10.1117/12.239093

Wu, S.-Y., Turner, T. L., and Rizzi, S. A. (2000). "Piezoelectric shunt vibration damping of F-15 panel under high acoustic excitation," in Proceedings of SPIE The International Society for Optical Engineering (Newport Beach).

Xie, S., Li, P., Zhang, X., and Yan, B. (2014). Vibration suppression of structure with electromagnetic shunt damping absorber. Int. J. Appl. Electrom. 45, 395-402. doi: 10.3233/JAE-141856

Yan, B., and Zhang, X. N. (2012). Vibration isolation of a beam via negative resistance electromagnetic shunt dampers. J. Intell. Mater. Syst. Struct. 23, 665-673. doi: 10.1177/1045389X12437889

Zhou, B., Thouverez, F., and Lenoir, D. (2013). An adaptive control strategy based on passive piezoelectric shunt techniques applied to mistuned bladed disks. J. Comput. Appl. Math. 246, 289-300. doi: 10.1016/j.cam.2012.06.023

Zorić, N. D., Simonović, A. M., Mitrović, Z. S., and Stupar, S. N. (2012). MultiObjective fuzzy optimization of sizing and location of piezoelectric actuators and sensors. FME Transac. 40, 1-9. Available online at: https://www.mas.bg.ac. rs/istrazivanje/fme/vol40

Conflict of Interest Statement: The authors declare that the research was conducted in the absence of any commercial or financial relationships that could be construed as a potential conflict of interest.

Copyright (c) 2019 Marakakis, Tairidis, Koutsianitis and Stavroulakis. This is an open-access article distributed under the terms of the Creative Commons Attribution License (CC BY). The use, distribution or reproduction in other forums is permitted, provided the original author(s) and the copyright owner(s) are credited and that the original publication in this journal is cited, in accordance with accepted academic practice. No use, distribution or reproduction is permitted which does not comply with these terms. 